\title{
Prevalence of Multiple Sclerosis in the Metropolitan Area of Edirne City, Turkey
}

Yahya Çelik1, Özlem Birgili², Aslı Kiyat , Baburhan Güldiken¹, Hülya Özkan², Hakan Yılmaz², Sebahattin Saip ${ }^{3}$, Dilek Kuşçu', Nevin Sütlas" ${ }^{4}$, Jale Ağaoğlư ${ }^{5}$, Ufuk Utku', Aksel Siva ${ }^{3}$

${ }^{1}$ Department of Neurology, School of Medicine, Trakya University, Edirne, Turkey

${ }^{2}$ Department of Neurology, Edirne State Hospital, Edirne, Turkey

${ }^{3}$ Cerrahpaşa Medical Faculty, Department of Neurology, İstanbul University, Istanbul, Turkey

${ }^{4}$ Department of Neurology, Bakırköy State Hospital, Istanbul, Turkey

${ }^{5}$ Department of Neurology, Okmeyadanı State Hospital, Istanbul, Turkey

\begin{abstract}
Objective: The prevalence and incidence of multiple sclerosis may vary according to the influence of the altitude of a geographical area as well as the genetic and environmental factors. This study ained to determine the incidence and prevalence of multiple sclerosis in Edirne population.

Material and Methods: Patients with a definite diagnosis of MS according to McDonald's criteria, admitted to one of the three MS clinics in Edirne, were included in this two-stage study. Also the records of hospitals in İstanbul serving patients from Edirne, have been evaluated.

Results: The prevalence rate of confirmed MS patients was 33.9/100000 (95\% Cl: 32-36) in 2003. The mean annual incidence was 3.48/100000 (95\% Cl: 2.90-4.00). Mean age of the patients was $36.5 \pm 9.6$ years. Mean age at onset was $29.2 \pm 8.5$ years. Mean duration of disease was $6.9 \pm 5.2$ years. Overall, $69.2 \%$ had a relapsing-remitting course, $20.5 \%$ had a primary progressive course and $10.3 \%$ had a secondary progressive course. Mean Expanded Disability Status Scale score was 3.04 \pm 2.18 . The prevalence and annual incidence after one year was 36.5 per 100000 (95\% Cl: 33.2-38.6) and 2.60 per 100000 (95\% Cl: 2.1-3.8), respectively.
\end{abstract}

Conclusion: This is the first city-based MS prevalence study performed in Turkey. The MS prevalence in Edirne is similar to that of Greece and Bulgaria but lower than that of European countries.

Key Words: Multiple Sclerosis, prevalance, incidence, epidemiology, Turkey

Received: 08.04.2010 Accepted: 12.04.2010

\section{Introduction}

Multiple sclerosis (MS) is an acquired neuroinflammatory and neurodegenerative immune-mediated disease of the CNS, characterized by inflammation, demyelination and axonal loss. It is one of the most common causes of neurological disability in young adults after trauma.

In addition to the influence of genetic and environmental factors, the prevalence and incidence of MS may vary according to the altitude of the geographical area. MS prevalence is high (50-100/100 000) in Europe, North America, and New Zealand and is low ( $\leq 5 / 100000)$ in the Far East, Africa, Asia, and South America (1).

The distribution of MS is not homogenous in Europe, North America, and New Zealand. The highest MS prevalence rates in Europe are found in England, Denmark, and the Scandinavian countries. It has been reported that the MS prevalence rates in Southern Europe are low-medium (2). However, it has also been shown that newly reported MS prevalence rates were higher than previously reported in Italy, Spain, Cyprus, and the Balkans (3-7).
This latitude-related model does not explain the distribution of MS prevalence rates in the Mediterranean areas. Recent epidemiological studies conducted in the two largest Mediterranean islands, Sardinia and Sicily, demonstrated very high prevalence rates of 151/100 000 (8) and 120/100 000 (9), respectively.

On the other hand, MS prevalence rates in countries neighboring Turkey were lower; 38.9/100 000 in Greece (10), 39.3/100 000 in Bulgaria (11-13), and 35.5/100 000 in Iran (14).

Recently, Turk Boru et al. reported a prevalence rate in the Maltepe district of Istanbul, which is much higher than the rate we previously found and reported $(15,16)$. There has been only one door to door study of MS prevalence rates in Turkey (16). This survey on the prevalence of MS in the district of Maltepe, Istanbul, Turkey, has shown a MS prevalence rate of 101.4 per 100000 . The methodological design used in the Turk-Boru et al. study has been used in various studies (16). The rate of prevalence they observed was much higher than those of both neighboring countries and ours (11-15). We had previously reported the preliminary part of our study as a poster (15). We re-evaluated new MS cases in the prevalence 
area and combined them with MS incidence and prevalence rates observed in 2004.

This study was conducted to determine the prevalence rate of MS in the metropolitan area of Edirne city in Turkey, and to compare it with that from the most recent epidemiological studies in our country and neighboring countries.

\section{Materials and Methods}

\section{Geographic location of the study area}

Edirne is located in the northwestern part of Turkey at the border of Greece and Bulgaria, between $40^{\circ} 30^{\prime}-42^{\circ} 20^{\prime}$ north latitude and $26^{\circ}-27^{\circ}$ east longitude degrees (Figure 1). It covers an area of 6276 square kilometers. The topography consists of plains and rolling hills with an average elevation of 41 meters above sea level. It is a relatively flat area. Since Edirne is not too far from the sea, winters are generally mild, at times with rain, but at times they can be colder, with snow. Summers are hot and dry, and Spring and Fall are rainy. The average annual temperature is $13.5^{\circ} \mathrm{C}$ with an annual precipitation of $600 \mathrm{~mm}$.

\section{Population Structure}

The official number of inhabitants is 119298 in the metropolitan study area (census 2000) (17). The region is ethnically heterogeneous, being inhabited by Romanies (also known as Gypsies; origins in India) ( $15-20 \%)$, Caucasians with origins in the Balkans $(-40-60 \%)$, and persons of Anatolian origin ( 20-45\%).

\section{Study Design}

Health care in Turkey is currently provided mainly by the state through three health insurance systems that cover health care in university hospitals, state hospitals and social security hospitals. This also applies to Edirne, and all neurologists in this city work in one of these three types of institutions. There are four neurologists in the Department of Neurology at the University Hospital, two neurologists in the neurology section in the State Hospital, and one neurologist in the neurology section at the Social Security Hospital. All people with a diagnosis of MS or symptoms suggestive of MS would be admitted to the neurology department of one of these hospitals. The major alternative to healthcare in Edirne is Istanbul, where three major MS clinics (one university hospital, one social security hospital, one state hospital) are all located (in the European part of Turkey, the same as Edirne). These three were included in the study to screen referrals from Edirne, in order to determine if there were people with MS who were admitted without being seen in their home city. Patient records in these centers were also compared with the Edirne prevalence cohort for concurrent cases. The registry of MS patients on disease modifying drugs from Edirne was also analyzed.

\section{Evaluation of the Patients}

Based on patient records, the total number of people with a diagnosis of MS living in the metropolitan area of Edirne at the time of the study and for at least one year (between July 1, 2002 and June 30, 2003) who had been seen in any of these centers was determined. All patients were invited to their primary care center or contacted by phone for final evaluation

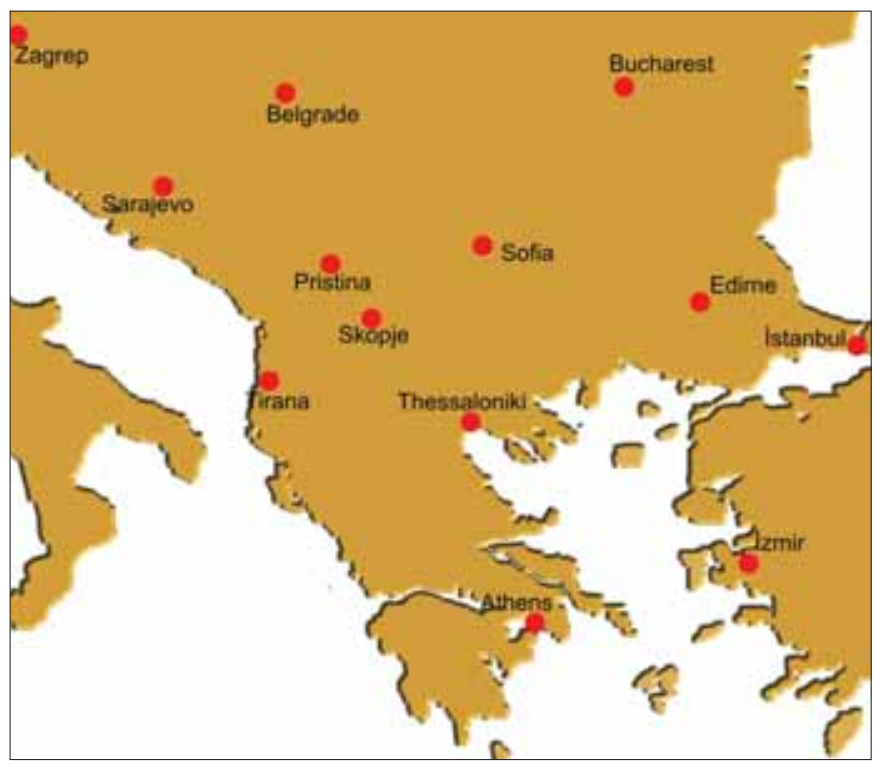

Figure 1. The geographical map of Edirne city

between March 2003 and June 2003. Patients with confirmed clinical MS diagnoses after one year were re-screened using the records of the three Edirne medical centers (dates: July 1, 2003 and June 30, 2004). Annual MS incidence and prevalence rates were then calculated for this period.

The diagnosis was made according to McDonald's criteria (2000) (18) and patients with clinically and/or laboratoryconfirmed MS were included. Demographic and clinical data, including clinical onset, symptoms, disease course, duration of disease, and final Expanded Disability Status Scale (EDSS), were recorded. Cerebrospinal fluid levels were tested in 19 patients, neurophysiologic (evoked potential) studies were recorded from 29 patients, and neuroimaging (cranial and/or spinal cord MRIs) was performed for 39 patients, but this data was not included in this study. Disability was assessed with the expanded disability status scale of Kurtzke (19). If there was a gap in patient information, the patient was re-evaluated by a member of the study group. All patients' MRI results were consistent with MS.

\section{Results}

The total number of people who had received a diagnosis of MS and were living in the metropolitan area of Edirne for at least one year was found to be 39 . The rough prevalence of MS was estimated to be 33.9 per 100000 (95\% Cl: 32-36). The number of new cases who had received a diagnosis of MS was four between June 1, 2002 and July 31, 2003, corresponding to an annual incidence rate of 3.48 per 100000 (95\% Cl: 2.94.0) for this time period. The female-male ratio in the total population was 2.55:1 [28 female (71.8\%), 11 male (28.2\%)].

The mean age of the patients at the time of the study was $36.5 \pm 9.6$ (range: $21-60$ ). The mean age of onset of MS in the study population was $29.2 \pm 8.5$ (range: $16-46$ ). The mean duration of disease was $6.9 \pm 5.2$ years (range: $0-22$ ). The mean EDSS score was 3.04 \pm 2.17 (range: 0-8.5) (mean EDSS for females: $3.6 \pm 2.2$; for males: $3.0 \pm 2.3$ ). 
The highest rates were observed as 89.1 in the 30 to 34 year age group for women, 33.6 in the 55-59 year age group and 30.2 in the 25-29 year age group for men.

The clinical courses were as follows: 27 cases (69.2\%) were relapsing-remitting (RR), eight cases $(20.5 \%)$ were secondary progressive (SP), and four cases (10.3\%) were primary progressive or progressive relapsing (PP).

Twenty-six of the patients were born in Edirne. Seven patients with MS currently living in Edirne were also evaluated in one of the three major reference MS clinics in Istanbul. All of them were also seen and had records in one of the Edirne hospitals. Screening of the patient records in the Istanbul centers indicated that these seven patients were the only patients from Edirne who had been seen there during the study period.

Three new cases received a diagnosis of MS between June 1, 2003 and July 31, 2004 (two female, one male), corresponding to an annual incidence rate of 2.60 per 100000 (95\% $\mathrm{Cl}$ : 2.1-3.8) for this time period. No patients died or moved away from Edirne during this period.

The total number of clinically confirmed MS patients was 42 , corresponding to a prevalence rate of 36.5 per 100000 (95\% Cl: 33.2-38.6). The clinical course of all patients newly diagnosed between June 1, 2003 and July 31, 2004 was RR. The mean EDSS for the 42 patients was calculated again and found to be $3.0 \pm 2.1$ [mean EDSS for females: $3.4 \pm 2.1$; for males: $2.9 \pm 2.1]$.

\section{Discussion}

Studies indicate highly variable MS prevalence rates in different parts of the world. MS prevalence rates can even change in the same country (1). This finding is important in view of the relationships between MS and environmental, genetic, ethnic, and geographical factors. Turkey is a country situated between Europe and Asia, and is characterized by different ethnic populations and variable geographic environments. For these reasons, MS prevalence rates in Turkey can provide important clues towards the understanding of genetic and geographical distributions of the disease.

This study has shown the prevalence rate of MS to be no less than 33.9/100 000 and the annual incidence rate of MS to be $3.48 / 100000$ in the metropolitan area of Edirne city in Turkey. It is possible that certain cases have been missed as we included only confirmed MS patients in the study. Therefore, a slightly higher actual prevalence rate may be expected. The levels of incidence and prevalence in our study confirm that Edirne is a high risk area for multiple sclerosis.

After one year, when we re-screened the new MS patients in the Edirne city centers, three new clinically confirmed MS patients were found. Annual incidence and prevalence rates were calculated as 2.60 per 100000 and 36.5 per 100 000, respectively.

The only other study reporting MS prevalence rates is the work of Turk Boru et al., which found a high rate of 101.4 per 100000 in the Maltepe district of Istanbul (16). The methodology used in this study was different from ours, as they conducted a door to door survey. Although such a design may be more sensitive than our methods, this design also has its limitations for diseases such as MS. The average age of patients and duration of disease was $41 \pm 12.0$ and $7.4 \pm 5.8$ years, respectively, which differs significantly from our MS population. However, when the two studies are compared after age and gender adjustment, these differences (MS rates and demographic characteristics, such as age, of both groups) become insignificant. The prevalence rate and average age of patients in this study was much higher than in our study, and was also higher than epidemiological studies carried out in neighboring countries $(11-15,20)$.

The first part of our study was reported initially in an abstract form (15). Then, in the extension period when the study population was re-evaluated, we did not find a significant difference from our earlier results. We re-evaluated new MS cases in the prevalence area and searched for MS incidence and prevalence rates during 2004.

Turk Boru et al. study (16) is the only published study on MS prevalence in Turkey. It was a cross-sectional field research study using door-to-door sampling in the Maltepe district of Istanbul. This study found the prevalence of MS in Maltepe to be $101.4 / 100000$ within the total population. The average age of patients was $41 \pm 12.0$ years. The prevalence rate and average age of patients in the Turk Boru study are much higher than those found in our study and in epidemiological studies carried out in neighboring countries (20). In addition, high MS prevalence rates in the central Istanbul district of Maltepe do not necessarily represent the prevalence of MS in Istanbul as a whole and/or in Turkey, because of the high and dense population in Istanbul. We may emphasize that the rate reported in our study may be lower than the actual rate, since it is solely based on clinically confirmed MS, according to McDonalds criteria 2001. Many more actual cases may exist, but were not counted in our study because they did not fulfill these criteria. However, the patients who would be missed would be cases with either very benign forms of MS or misdiagnosed cases, and these missed cases would not be expected to exceed a small fraction of the confirmed cases. In addition, the followup screening a year later gave similar results, suggesting that the number of missed cases may be limited. We therefore believe that the prevalence rate detected in our study is broadly consistent with the actual prevalence rate in the study region. Similar prevalence rates were reported for neighboring countries $(10,11,13)$. Yet, it is still possible that different prevalence rates may be found in different regions in Turkey, as ethnic backgrounds are heterogeneous throughout the country.

In a very small study on the Jewish population living in Istanbul, the prevalence rate of MS was found to be $111 / 10^{5}$ among the Turkish-Jewish community in Istanbul, which is about three times higher than the prevalence rate found in the Edirne MS population (21) and close to the Turk-Boru findings. However, this rate is also higher than that found in a recent Israeli study, in which Karni et al. (22). studied the ageadjusted incidence and possible prevalence of MS in a more recent sample in different population groups, including Arabs, of Greater Jerusalem. The prevalence rates were found to be 64.3 for European/American Jews, 22.1 for African/Asian Jews, 63.5 for Israel-born European/American Jews, 52.1 for Israel-born African/Asian Jews and 19.2 for Arabs. The similarities and differences in the MS prevalence rates between groups suggested that these rates were probably due to en- 
vironmental factors (22). It should be kept in mind that the Jewish community in Istanbul is a small and closed community. The higher familial cases found in this might be noteworthy.

In Bulgaria, which borders the Edirne region of Turkey, MS prevalence rates were found to be 30.2/100 000 in Sofia city center, 39.1/100 000 and 39.3/100 000 in two rural areas $(11,12)$. MS prevalence rates in Romanies living in Bulgaria were reported as 18.4-19.1 / 100000 (13). It is thought that the Romany ethnic group originated from North India. As the Romany origin is Asian, it is not surprising that MS prevalence in Romanies is lower than MS prevalence in Europe and the Balkans (23). The Romanies settled in the Balkan area in the $14^{\text {th }}-15^{\text {th }}$ centuries. Their population is highly homogenous since marriages are only to other Romanies, restricting marriage to a relatively small pool. Romanies composed $15-20 \%$ of our study population. MS prevalence in Edirne was lower than in Greece and Bulgaria. Because the number of Romanies with MS in our study group was too small to conduct a separate analysis with adequate statistical power, MS prevalence in the Romany population in Edirne could not be evaluated.

In the Evros area of Greece, which borders the Edirne area of Turkey, MS prevalence and incidence is reported as $38.9 / 100000$ and 2.36/100 000, respectively (10). MS prevalence in the Greek population of Cyprus was found to be 42 $44.5 / 100$ 000, and these rates are greater than in the Greek population living in Greece $(3,24)$.

While MS prevalence in the Turkish population living in Cyprus was found to be 46.5-55.7/100 000, in those Cypriots who had emigrated from Turkey, the prevalence was 17.1-24.5/100 000. In the same study, MS prevalence among Turkish Cypriots born in Cyprus was found to be higher than among Greek Cypriots born in Cyprus $(3,24)$.

The study reported in 1998 by the Turkish Multiple Sclerosis Study Group was a multi-center study in which demographic and clinical factors, including prognostic factors, were studied in 1259 patients from nine major MS centers from different parts of Turkey (25). The mean age at onset and duration of disease in this study was $27.6 \pm 8.8$ and $8.44 \pm 6.7$ years, respectively. The rates of the clinical course were $62 \%$ for RR MS, $12.2 \%$ for PP MS, and $25.8 \%$ for SP MS. These rates were similar to the Edirne cohort and those presented in other previous Western series (26).

However, this first city-based MS prevalence study may not be representative of all other areas in Turkey, due to a wide variation in social, cultural and ethnic factors, as well as due to geographical differences seen in this country. Future surveys of MS in Turkey may find a greater prevalence of the illness than found in our study.

\section{Conflict of Interest}

No conflict of interest was declared by the authors.

\section{References}

1. Ebers GC, Sadovnick AD. Epidemiology. In Paty DW, Ebers GC eds. Multiple sclerosis. Philedelphia: FA Davis 1998;5-28.

2. Rosati G, Granieri E, Carreras M, Tola R. Multiple sclerosis in southern Europe: a prevalence study in the sociosanitary district of Copparo, northern Italy. Acta Neurol Scand 1980;62:244-9. [CrossRef]
3. Dean G, Aksoy H, Akalin T, Middleton L, Kyriallis K. Multiple Sclerosis in the Turkish- and Greek-speaking communities of Cyprus. J Neurol Sci 1997;145:163-8. [CrossRef]

4. Granieri E, Malagu S, Casetta I, Tola MR, Govoni V, Paolino E, et al. Multiple sclerosis in Italy. Arch Neurol 1996;53:793-8. [CrossRef]

5. Casquero P, Villoslada P, Montalban X, Torrent M. Frequency of multiple sclerosis in Menorca, Balearic Islands, Spain. Neuroepidemiology 2001;20:129-33. [CrossRef]

6. Bufill E, Blesa R, Galan I, Dean G. Prevalence of multiple sclerosis in the region of Osona, Catalonia, northern Spain. J Neurol Neurosurg Psychiatry 1995;58:577-81. [CrossRef]

7. Benito-Leon J, Martin E, Vela L, Villar ME, Felgueroso B, Marrero C, et al. Multiple sclerosis in Mostoles, central Spain. Acta Neurol Scand 1998;98:238-42.

8. Granieri E, Casetta I, Govoni V, Tola MR, Marchi D, Murgia SB, et al. The increasing incidence and prevalence of MS in a Sardinian province. Neurology 2000;55:842-8.

9. Grimaldi LM, Salemi G, Grimaldi G, Rizzo A, Marziolo R, Lo Presti $C$, et al. High incidence and increasing prevalence of MS in Enna (Sicily), southern Italy. Neurology 2001;57:1891-3.

10. Piperidou HN, Heliopoulos IN, Maltezos ES, Milonas IA. Epidemiological data of multiple sclerosis in the province of Evros, Greece. Eur Neurol 2003;49:8-12. [CrossRef]

11. Milanov I, Georgiev D, Kmetska K, Jordanova L, Topalov N. Prevalence of Multiple Sclerosis in Bulgaria. Neuroepidemiology 1997;16:304-7. [CrossRef]

12. Georgiev D, Milanov I, Tzonev V, Kalafatova O. The epidemiology of multiple sclerosis in Sofia. In Firnhaber W, Lauer K eds. Multiple Sclerosis in Europe. An Epidemiological Update. Alsbach: Leuchttrum-Verlag/LTV Press, 1994;322-5.

13. Milanov I, Topalov N, Kmetski T. Prevalence of multiple sclerosis in Gypsies and Bulgarians. Neuroepidemiology 1999;18:218-22. [CrossRef]

14. Etemadifar M, Janghorbani M, Shaygannejad V, Ashtari F. Prevalence of multiple sclerosis in Isfahan, Iran. Neuroepidemiology 2006;27:39-44. [CrossRef]

15. Celik Y, Birgili O, Kiyat A, Guldiken B, Yilmaz H, Saip S, et al. Prevalence of multiple sclerosis in the metropolitan area of Edirne city, Turkey. Multiple Sclerosis ECTRIMS 2003;211.

16. Turk Boru U, Alp R, Sur H, Gul L. Prevalence of multiple sclerosis door-to-door survey in Maltepe, Istanbul, Turkey. Neuroepidemiology 2006;27:17-21.

17. T.C. Basbakanlik Devlet Istatistik Enstitusu. 2000 Genel Nufus Sayimi. T.C. Basbakanlik Devlet Istatistik Enstitusu, 2000.

18. McDonald WI, Compston A, Edan G, Goodkin D, Hartung HP, Lublin FD, et al. Recommended diagnostic criteria for multiple sclerosis: guidelines from the International Panel on the diagnosis of multiple sclerosis. Ann Neurol 2001;50:121-7. [CrossRef]

19. Kurtzke JF. Rating neurologic impairment in multiple sclerosis: an expanded disability status scale (EDSS). Neurology 1983;33:1444-52. [CrossRef]

20. Pugliatti M, Rosati G, Carton H, Riise T, Drulovic J, Vecsei L, et al. The epidemiology of multiple sclerosis in Europe. Eur J Neurol 2006;13:700-22. [CrossRef]

21. Siva A, Uyanik O, Saip S, Tanik O, Agaoglu J, Isik N, et al. Prevalence rate of multiple sclerosis in the jewish community in Istanbul. J Neurologic Sciences 2005;238:S249. [CrossRef]

22. Karni A, Kahana E, Zilber N, Abramsky O, Alter M, Karussis D. The frequency of multiple sclerosis in jewish and arab populations in greater jerusalem. Neuroepidemiology 2003;22:82-6. [CrossRef]

23. Kalman B, Takacs K, Gyodi E, Kramer J, Fust G, Tauszik T, et al. Sclerosis multiplex in gypsies. Acta Neurol Scand 1991;84:181-5.

24. Middleton LT, Dean G. Multiple Sclerosis in Cyprus. J Neurol Sci 1991;103:29-36. [CrossRef]

25. Kantarci O, Siva A, Eraksoy M, Karabudak R, Sutlas N, Agaoglu J, et al. Survival and predictors of disability in Turkish MS patients. Turkish Mutiple Sclerosis Study Group (TUMSSG). Neurology 1998;51:765-72.

26. Weinshenker BG. The natural history of multiple sclerosis. Neurol Clin 1995;13:119-46. 